\title{
Regulatory Gaps in Drug Compounding: Implications for Patient Safety, Innovation, and Fraud
}

Joanna Shepherd

Follow this and additional works at: https://via.library.depaul.edu/law-review

Part of the Law Commons

\section{Recommended Citation}

Joanna Shepherd, Regulatory Gaps in Drug Compounding: Implications for Patient Safety, Innovation, and Fraud, 68 DePaul L. Rev. (2019)

Available at: https://via.library.depaul.edu/law-review/vol68/iss2/12

This Article is brought to you for free and open access by the College of Law at Digital Commons@DePaul. It has been accepted for inclusion in DePaul Law Review by an authorized editor of Digital Commons@DePaul. For more information, please contact digitalservices@depaul.edu. 


\title{
REGULATORY GAPS IN DRUG COMPOUNDING: IMPLICATIONS FOR PATIENT SAFETY, INNOVATION, AND FRAUD
}

\author{
Joanna Shepherd*
}

\section{Contents}

INTRODUCTION ................................... 385

I. Background on Drug Compounding ............. 387

A. Adverse Events .......................... 388

B. Risks to Innovation and Competition ............ 390

C. Fraud Concerns ............................ 393

II. Federal Regulation of Compounding Facilities . 394

III. Regulatory Gaps in Drug Compounding ......... 396

IV. Closing the Regulatory Gaps in Compounding .. 398

A. Encouraging Transition of Compounders to 503B

Outsourcing Facilities ........................ 398

B. Restricting Compounded Copies of FDA-Approved Drugs .................................. 400

C. Improving Regulation of Bulk Drug Substances..... 401

D. Increasing FDA Oversight of Compounding Facilities ................................ 402

E. Expanding State Oversight of 503A Compounding Pharmacies.................................... 404

Conclusion ........................................ 404

\section{INTRODUCTION}

Drug compounding is the practice of mixing, combining, or altering drug ingredients to create a product that meets the medical needs of a patient whose needs cannot otherwise be met with commerciallyavailable products. Compounding is essential for patients that are allergic to certain ingredients or cannot tolerate the route of administration or dosage form of a commercially-available drug. Compounding may also enable pharmacists to supply medications when there is a shortage of commercially-available drugs. For example, amid the nationwide shortage of generic liquid Tamiflu and growing flu deaths in

* Professor of Law, Emory University School of Law. 
early 2018, pharmacists around the country used Tamiflu capsules to compound a liquid version of the drug. ${ }^{1}$

Although drug compounding fills a critical need for many patients, it has also given rise to significant drug safety concerns, fraud, and anticompetitive practices. Every year, many patients experience harmful side effects and even death from compounded drugs that are contaminated or made in excessive potency because of pharmacist error. The ability of pharmacies to make and dispense drugs outside of the typical channels has also given rise to extensive fraud. Pharmacists, doctors, and company executives are routinely prosecuted for schemes to defraud insurers and the federal government into paying hundreds of millions of excess dollars for compounded drugs. In addition, some rogue pharmacies earn significant profits by mass-producing compounded drugs that are essentially copies of commercially-available drugs. These facilities put patients at risk by needlessly exposing them to unapproved drugs and jeopardize drug innovation by reducing manufacturers' incentives to invest in the development of new products.

Many of the drug safety problems, fraudulent practices, and anticompetitive behaviors are facilitated by regulatory gaps in the oversight of drug compounding. Traditional drug manufacturers must prove that their drugs are safe and effective and manufactured in accordance with current good manufacturing practices (CGMPs) in order to obtain U.S. Food and Drug Administration (FDA) approval. In contrast, compounders need not obtain FDA approval for their drugs before selling them, and most compounders do not have to produce drugs in accordance with CGMPs. Moreover, traditional drug manufacturing facilities are subject to routine inspection by the FDA to ensure they comply with CGMPs and there are no other safety or quality concerns. In contrast, most compounders are not primarily overseen by the FDA but by state boards of pharmacy that are less consistent in their oversight - in fact, fewer than half of the states conduct routine inspections of compounding pharmacies. Finally, whereas traditional manufacturers are required to report adverse events involving their drugs to the FDA, most compounders do not have to report adverse events to either the FDA or state regulatory authorities.

This Article explains the regulatory gaps in drug compounding that give rise to drug safety problems, fraud, and anticompetitive behavior.

1. Elizabeth Weise, Liquid Flu Drug Tamiflu in Short Supply in Some Areas, USA TodAY (Jan. 10, 2013), https://www.usatoday.com/story/news/nation/2013/01/10/tamiflu-flu-drugshortage/1820373/. 
It also proposes various measures that could be taken to close the gaps in order to protect patients, payors, and innovation.

\section{BACKground on Drug Compounding}

Drug compounding is the alteration of a drug or drug ingredient into a form that meets the medical needs of a patient that cannot otherwise be met with an FDA-approved product. In these situations, pharmacists (or physicians) may mix, combine, or alter the ingredients into a more appropriate compounded drug product. For example, patients may require compounded drug products if they are allergic to a particular ingredient in an approved drug, cannot tolerate the particular taste of an approved drug, or require a different dosage form such as a liquid instead of a tablet. Compounding serves an important purpose in ensuring that patients with unique needs receive medicallyappropriate drugs. ${ }^{2}$

All pharmacists receive training in simple compounding, and most pharmacies occasionally perform basic compounding services when patients present a valid prescription for a compounded drug. However, whereas just a few decades ago pharmacy compounding was limited to local pharmacists making medically-necessary drugs for individual patients, today many compounders are involved in largescale production and multistate distribution of compounded products. ${ }^{3}$ Currently, over $65 \%$ of independent pharmacies engage in compounding, ${ }^{4}$ and approximately 7,500 pharmacies across the country specialize in preparing compounded drugs. ${ }^{5}$ Over 40 million compounded prescriptions are dispensed each year, ${ }^{6}$ earning over $\$ 6$ billion annually. This revenue is expected to double by $2024 .^{7}$

2. Agata Dabrowska, Cong. Research Serv., R45069, Drug Compounding: FDA Authority AND Possible Issues for Congress 1 (2018).

3. Janet Woodcock \& Julie Dohm, Toward Better-Quality Compounded Drugs - An Update from the FDA, 377 NEw Eng. J. MED. 2509, 2509 (2017).

4. Craig Ruark, Compound Pharmacies Spread to Meet Need for Customized Prescriptions in Southern Nevada, Las Vegas Bus. Press (Sept. 11, 2016), https:/businesspress.vegas/economy/ small-business/compound-pharmacies-spread-to-meet-need-for-customized-prescriptions-insouthern-nevada/.

5. Frequently Asked Questions About Pharmaceutical Compounding, Aм. Pharmacists Ass'N, http://www.pharmacist.com/frequently-asked-questions-about-pharmaceutical-com pounding (last visited Jan. 25, 2019).

6. See Ruark, supra note 4.

7. Global Markets Insights, Inc., Compounding Pharmacies Market to Cross More than \$12 Billion by 2024, PRNewswire (June 6, 2017), https://www.prnewswire.com/news-releases/com pounding-pharmacies-market-to-cross-more-than-12-billion-by-2024-global-market-insights-inc626705911.html. 
This expanding practice has, effectively, outgrown the laws designed to regulate it. Before explaining the gaps in the regulation of compounding pharmacies, this Section describes the significant drug safety concerns, fraud, and anticompetitive behavior that plague the industry.

\section{A. Adverse Events}

The Federal Food, Drug, and Cosmetic Act (FDCA) requires that the FDA approve all new drugs as "safe" and "effective" before the drugs are marketed for sale. ${ }^{8}$ However, although compounded drugs are new drugs, Congress has deemed it infeasible for pharmacists to obtain approval for each compounded drug made to meet the unique needs of an individual patient. 9 As a result, compounded drugs are not evaluated for safety, efficacy, or quality prior to sale, making them inherently riskier than traditional new drugs. In addition to the greater inherent risk of compounded drugs, most compounding facilities are not held to the same quality standards as traditional manufacturing facilities. The lax oversight of these facilities has resulted in numerous instances of contamination, pharmacist error, and generally unsanitary conditions.

Several adverse events involving compounded drugs have resulted in serious patient injury and death. One of the most tragic events involving compounded drugs occurred in 2012 when contaminated steroid injections compounded at the New England Compounding Center in Massachusetts caused a fungal meningitis outbreak that sickened over 753 people and caused 64 deaths in Massachusetts. ${ }^{10}$ That same year, a compounding pharmacy in Florida dispensed contaminated eye medications that caused fungal eye infections, vision loss, or both in 47 patients. ${ }^{11}$ A year earlier, a compounding pharmacy in Alabama sold contaminated intravenous (IV) fluids that resulted in 19 cases of bacterial infections, 9 of which resulted in death. ${ }^{12}$ Between 2001 and

8. See Federal Food, Drug, and Cosmetic Act, 21 U.S.C. § 355(b)(1) (2012 \& Supp. V 2018).

9. See Thompson v. W. States Med. Ctr., 535 U.S. 357, 369-70 (2002) ("[I]t would not make sense to require compounded drugs created to meet the unique needs of individual patients to undergo the testing required for the new drug approval process. . . Pharmacists do not make enough money from small-scale compounding to make safety and efficacy testing of their compounded drugs economically feasible, so requiring such testing would force pharmacists to stop providing compounded drugs.").

10. Multistate Outbreak of Fungal Meningitis and Other Infections, CTRS. FOR DisEASE CONTrol \& Prevention (Oct. 30, 2015), https://www.cdc.gov/hai/outbreaks/meningitis.html.

11. Christina A. Mikosz et al., Fungal Endophthalmitis Associated with Compounded Products, 20 Emerging Infectious Diseases 248, 248 (2014).

12. Tom Watkins, Contaminated IV Solution Suspected in 9 Patient Deaths in Alabama, CNN (Mar. 29, 2011), http://www.cnn.com/2011/HEALTH/03/29/alabama.hospitals.deaths. 
2012, over 40 adverse events were reported at compounding pharmacies, resulting in over 1,100 reported cases of serious injury and 115 deaths. ${ }^{13}$ The vast majority of these adverse events were caused by either contamination or drugs compounded with potency far in excess of the recommended strength.

In response to these adverse events, and especially the 2012 fungal meningitis outbreak, Congress enacted the Compounding Quality Act as part of the Drug Quality and Security Act of 2013 (DQSA). ${ }^{14}$ As I describe more fully in Section III, this Act amended the FDCA by dividing compounding pharmacies into two categories with separate regulatory oversight requirements.

Despite the increased regulatory oversight provided by the DQSA, drug compounding continues to produce adverse events. Many recent adverse events result from contamination in the preparation and handling of compounded drugs. For example, in 2016, contamination of IV solutions at a compounding pharmacy in New York caused fungal bloodstream infections in 17 patients and resulted in 2 deaths. ${ }^{15}$ Similarly, in 2017, 43 patients experienced vision loss after receiving eye injections dispensed from a compounding pharmacy in Texas. ${ }^{16}$ Upon investigation of the pharmacy, the FDA noted that their "drug products intended or expected to be sterile were prepared, packed, or held under insanitary conditions, whereby they may have become contaminated with filth or rendered injurious to health."17

Adverse events also result from compounding errors such as the preparation of over- or under-potent drugs. As an example, in 2016, three infants were injected with opioid drugs distributed from an Indiana compounding pharmacy that were 25 times the recommended strength. ${ }^{18}$ That same year, seven patients developed a thyroid condi-

13. U.S. Illnesses and Deaths Associated with Compounded Medications or Repackaged Medications, Pew Charitable Tr. (June 23, 2017), http://www.pewtrusts.org/en/multimedia/data-vis ualizations/2017/us-illnesses-and-deaths-associated-with-compounded-medications-or-repack aged-medications.

14. Drug Quality and Security Act of 2013, Pub. L. No. 113-54, 127 Stat. 587 (codified at 21 U.S.C. § 301 et seq. (Supp. V 2018)).

15. Amber M. Vasquez et al., Notes from the Field: Fungal Bloodstream Infections Associated with a Compounded Intravenous Medication at an Outpatient Oncology Clinic-New York City, 2016, 65 Morbidity \& Mortality Wkly. Rep. 1274 (2016).

16. Woodcock \& Dohm, supra note 3, at 2510.

17. Letter from Monica R. Maxwell, Acting Dir., Office of Pharm. Quality Operations, Div. II, to Jack R. Munn, Guardian Pharmacy Servs. (Nov. 3, 2017), https://www.fda.gov/iceci/enforce mentactions/warningletters/2017/ucm586119.htm.

18. Press Release, U.S. Dep't of Justice, Pharmacy Owner and Director of Compliance Charged with Defrauding United States and Distributing Adulterated Drugs (June 22, 2017), https://www.justice.gov/usao-sdin/pr/pharmacy-owner-and-director-compliance-charged-defraud ing-united-states-and-1. 
tion after receiving super-potent compounded products from a compounding pharmacy in South Dakota. ${ }^{19}$

Other adverse events have resulted from compounders using unsafe ingredients to make new drugs. For example, in 2014, patients in several states experienced adverse events after receiving adulterated and misbranded drugs from a compounding pharmacy in New York. ${ }^{20}$ Similarly, in 2017, two patients in California suffered acute reactions and one died after receiving compounded IV solutions that contained a product not suitable for human consumption. ${ }^{21}$

The FDA reports that it has found unsanitary conditions or other violations in most of the 425 compounding pharmacies it has inspected after enactment of the DQSA, including dead insects, mold, and dog hair in the supposedly sterile compounding areas. ${ }^{22}$ During this same period, the FDA has overseen over 140 recalls of compounded drugs. ${ }^{23}$ Thus, although the DQSA may have increased regulation of compounding pharmacies, the pharmacies continue to pose a significant risk for patients receiving compounded drugs.

\section{B. Risks to Innovation and Competition}

In addition to creating public health risks, compounding pharmacies also pose a risk to innovation. The FDCA prohibits the compounding of drugs that are "essentially copies" of FDA-approved drugs unless there is a drug shortage. ${ }^{24}$ This restriction ensures that patients are not needlessly exposed to drugs held to a lower regulatory standard when their needs could be more safely met with an FDA-approved drug. The restriction also preserves the incentives for brand drug makers to develop innovative new drugs. It currently costs approximately $\$ 2.6$ billion to develop and bring each new drug to market with FDA ap-

19. U.S. Illnesses and Deaths Associated with Compounded Medications or Repackaged Medications, supra note 13.

20. Letter from Ronald M. Pace, Dist. Dir., New York Dist. Food \& Drug Admin., to Antonio Dos Santos, President, Medisca Pharmaceutique, Inc. (Nov. 25, 2015), https:/www.fda.gov/iceci/ enforcementactions/warningletters/2015/ucm474892.htm.

21. FDA Investigates Two Serious Adverse Events Associated with ImprimisRx's Compounded Curcumin Emulsion Product for Injection, U.S. Food \& Drug Admin. (Aug. 4, 2017), https:// www.fda.gov/Drugs/GuidanceComplianceRegulatoryInformation/PharmacyCompounding/ucm 570192.htm.

22. See Woodcock \& Dohm, supra note 3, at 2510.

23. See id.

24. U.S. Food \& Drug Admin., UCM510154, Compounded Drug Products That Are Essentially Copies of a Commercially Available Drug Product Under Section 503A of the Federal Food, Drug, and Cosmetic Act: Guidance for Industry (2018) [hereinafter UCM510154]. 
proval. ${ }^{25}$ Traditional drug makers would be less likely to invest in this costly drug development if compounding pharmacies could compound a similar substitute drug. ${ }^{26}$ These substitute drugs could be sold at a significantly lower price because the compounding pharmacy would not have to incorporate the $\$ 2.6$ billion cost of development into their pricing of the drug. Put simply, brand drug makers would not invest in developing new drugs if compounding pharmacies could free ride on their investment.

Even generic drug makers would be reluctant to invest in bringing new generics to market. ${ }^{27}$ Currently, generic drug makers must submit to the FDA an abbreviated new drug application (ANDA) for approval of a generic drug. Generic drug makers that demonstrate their drug is bioequivalent to a brand drug can rely on the brand drug maker's previously submitted safety and efficacy data, ${ }^{28}$ making the FDA approval process significantly faster and cheaper for generic drugs. However, even though the cost of bringing a new generic drug to market is only $\$ 1$ to $\$ 2$ million, ${ }^{29}$ generic drug makers would be less likely to make this investment if compounding pharmacies could compound similar drugs without going through the ANDA process.

Nevertheless, in violation of federal law, some rogue compounders are mass producing compounded drugs that are essentially copies of commercially-available drugs. ${ }^{30}$ The FDA has indicated that, in its inspections, it has found numerous compounding facilities that "were engaged in large-scale, non-patient specific compounding like a conventional manufacturer, without complying with premarket approval, labeling, and CGMP requirements for their drugs." ${ }^{1}$ These facilities

25. Joseph A. DiMasi et al., Innovation in the Pharmaceutical Industry: New Estimates of $R \& D$ Costs, 47 J. Health Econ. 20, 20 (2016).

26. Scott Gottlieb, 2018 Compounding Policies Priority Plan, U.S. Food \& Drug Admin. (Jan. 2018), https://www.fda.gov/Drugs/GuidanceComplianceRegulatoryInformation/Pharmacy Compounding/ucm592795.htm.

27. $I d$.

28. 21 U.S.C. $\$ 355(j)$ (iv) (2012 \& Supp. V 2018).

29. Expanding the Use of Generic Drugs, ASPE Issue Brief (Office Assistant Sec'y for Planning \& Evaluation, Washington, D.C.), Dec. 1, 2010; Henry Grabowski, Patents and New Product Development in the Pharmaceutical and Biotechnology Industries 7, 13 (Duke Univ., Dep't of Econ., Working Paper No. 2-25, 2002) ("Generic firms can file an Abbreviated New Drug Application (or ANDA), a process that takes only a few years and typically costs a few million dollars.").

30. Jeff Overley, 'Seminal' Allergan Cases Test Copycat Drug Limits, Law360 (Nov. 27, 2017, 11:08 PM), https://www.law360.com/articles/986982/-seminal-allergan-cases-test-copycat-druglimits.

31. U.S. Food \& Drug Admin., UCM536549, FdA's Human Drug Compounding Progress Report: Three Years After the Enactment of the Drug Quality \& Security Аст 12 (2017) [hereinafter UCM536549]. 
put patients at risk by needlessly exposing them to unapproved drugs and jeopardize drug innovation by reducing manufacturers' incentives to invest in the development of new products.

Part of the problem has stemmed from the FDA's policy on which ingredients can be used to compound drugs in 503B outsourcing facilities. Compounders can create new drugs by either altering an FDAapproved drug or starting fresh with a "bulk drug substance" (an active pharmaceutical ingredient) when the FDA-approved drug is medically inappropriate. Since the DQSA's enactment in 2013, the FDA has been working to establish a list of allowable bulk drug substances and has recently issued guidance designed to limit the situations in which bulk drug substances can be used in compounding and the specific substances that are approved for use. ${ }^{32}$ However, in the interim until the list is finalized, the FDA has generally allowed compounding with any drug substance that a compounder has nominated for the final list as long as it was nominated with sufficient information for the FDA to eventually evaluate the substance and it does not present a significant safety risk. ${ }^{33}$

Thus, the interim policy has authorized compounders to create drugs using many ingredients that have not yet been properly evaluated. Moreover, many compounders have exploited the interim policy to effectively recreate FDA-approved drugs using bulk drug substances. Under the DQSA, Congress intended that a bulk drug substance could not be used for compounding in a 503B outsourcing facility unless there was a clinical need determined after a notice and comment period. ${ }^{34}$ This notice and comment period would allow other drug makers to challenge the nomination of a bulk drug substance when, for example, an existing FDA-approved drug could meet the clinical need. However, under the interim policy, there is no official mechanism to oppose the nomination of a bulk drug substance before it is used in compounding. Instead, the only way to challenge the use of a bulk drug substance is through litigation such as that recently filed by Par Pharmaceutical, a unit of Endo International Plc. Par's lawsuit claims that the FDA's interim policy has resulted in the nomination and use of the ingredient vasopressin by compounder $\mathrm{QuVa}$

32. U.S. Food \& Drug Admin., UCM602276, Evaluation of Bulk Drug Substances Nominated for Use in Compounding Under Section 503B of the Federal Food, Drug, And Cosmetic Act: Guidance for Industry 6, 8 (2019) [hereinafter UCM602276].

33. U.S. Food \& Drug Admin., UCM469122, Interim Policy on Compounding Using Bulk Drug Substances Under Section 503B of the Federal Food, Drug, and Cosmetic Act: Guidance for Industry 1, 5, 7 (2017) [hereinafter UCM469122].

34. Drug Quality and Security Act of 2013, Pub. L. No. 113-54, § 102(a)(2)(A), 127 Stat. 587 (codified at 21 U.S.C. $§ 301$ et seq. (Supp. V 2018)). 
Pharma to create a new drug that is essentially a copy of Par's patented product Vasostrict. Vasostrict is the only FDA-approved drug containing vasopressin, and Par claims there is no evidence that Vasostrict is medically inappropriate for any patients. Thus, Par asserts that QuVa Pharma is using the loophole in the FDA's interim policy to evade pre-market approval and circumvent federal patent laws. 35

\section{Fraud Concerns}

The lack of regulatory oversight of compounding pharmacies has also invited fraud into the industry. Several pharmacies have been prosecuted for schemes to defraud insurers or the federal government into paying hundreds of millions of excess dollars for compounded drugs. The schemes generally involve compounding pharmacies charging payors exorbitant prices for compounded drugs that are medically unnecessary or not dispensed at all. ${ }^{36}$ Oftentimes, physicians are paid kickbacks to write prescriptions for the compounded drug and to direct patients to the pharmacy involved in the scheme. ${ }^{37}$ For example, in 2016, the Department of Justice named twenty-two defendants in insurance fraud cases that generated over $\$ 160$ million in fraudulent reimbursements from Medicare and TRICARE ${ }^{38}$ for compounded drugs. ${ }^{39}$ In 2017, the owner of a Florida compounding pharmacy pleaded guilty to generating over $\$ 100$ million in fraudulent reimbursements from Medicare, TRICARE, and private insurers. ${ }^{40}$ In 2018, the Department of Justice filed claims against a compounding pharmacy, two pharmacy executives, and a private equity firm for de-

35. Complaint at III 9, 10, 55, Par Sterile Products LLC v. Hargan, No. 1:17-cv-02221 (D.D.C. Oct. 26, 2017).

36. Julie Appleby, Fraud Concerns Emerge as Compounding Drug Sales Skyrocket, KAISER Health News (July 18, 2016), https://khn.org/news/fraud-concerns-emerge-as-compoundingdrug-sales-skyrocket.

37. Sheldon Bradshaw, Practitioners Take Huge Risks Dealing with Rogue Drug Compounders, 16 J. Drugs Dermatology 1308, 1310 (2017).

38. TRICARE is the health care program for the U.S. military. What is TRICARE?, TRICARE, https://tricare.com/what-is-tricare/ (last visited Feb. 5, 2019).

39. Press Release, U.S. Attorney's Office Cent. Dist. of Cal., U.S. Dep't of Justice, 22 Defendants Named in Healthcare Fraud Cases Involving over \$161 million in Fraudulent Bills to Government Healthcare Programs (June 22, 2016), https://www.justice.gov/usao-cdca/pr/22defendants-named-health-care-fraud-cases-involving-over-161-million-fraudulent-bills.

40. Press Release, Office of Pub. Affairs, U.S. Dep't of Justice, Owner of Florida Pharmacy Pleads Guilty in $\$ 100$ Million Compounding Pharmacy Fraud Scheme; Real Properties, Cars and a 50-Foot Boat Will Be Forfeited (Nov. 6, 2017), https://www.justice.gov/opa/pr/owner-floridapharmacy-pleads-guilty-100-million-compounding-pharmacy-fraud-scheme-real. 
frauding TRICARE out of tens of millions of dollars for compounded drugs. ${ }^{41}$

These and other fraudulent schemes impose hundreds of millions of dollars of unnecessary costs on the government, insurers, employers, and taxpayers. From 2006 to 2015, Medicare Part D's spending on compounded drugs grew by $625 \%$, with spending on compounded creams and gels increasing by 3,466\%. ${ }^{42}$ TRICARE's spending on compounded drugs increased by over 34,000\% from 2004 to 2015, from $\$ 5$ million to $\$ 1.75$ billion. ${ }^{43}$ State Workers' Compensation Plans have also experienced dramatic increases in reimbursements for compounded drugs; for example, the Texas Division of Workers' Compensation experienced a $46.4 \%$ increase in prescriptions for compounded drugs from 2010 to $2014 .{ }^{44}$ The various agencies charged with investigating insurance fraud fear a significant share of this spending increase is the result of fraud. ${ }^{45}$ Although traditional pharmacies have also been involved in insurance fraud schemes, the lack of regulatory oversight over drug compounding exacerbates the risk of fraud in compounding pharmacies.

\section{Federal Regulation of Compounding Facilities}

Under the FDCA, both brand name and generic drugs must be safe and effective and manufactured in accordance with CGMPs in order to obtain FDA approval. ${ }^{46}$ CGMPs are federal statutes governing the manufacturing, packaging, labeling, testing, and distribution of pharmaceutical products. These statutes ensure the drugs' identity, strength, quality, and purity. ${ }^{47}$ The FDA regularly inspects drug manufacturing facilities to ensure compliance with CGMPs. In contrast to manufacturing facilities that are regulated by the FDA, compounding

41. Press Release, Office of Pub. Affairs, U.S. Dep't of Justice, United States Files False Claims Act Complaint Against Compounding Pharmacy, Private Equity Firm, and Two Pharmacy Executives Alleging Payment of Kickbacks (Feb. 23, 2018), https://www.justice.gov/opa/pr/ united-states-files-false-claims-act-complaint-against-compounding-pharmacy-private-equity.

42. See Appleby, supra note 36.

43. Press Release, U.S. Attorney's Office Middle Dist. of Fla., U.S. Dep't of Justice, Government Intervenes in Lawsuit Against Florida Compounding Pharmacy for Excess Charges to TRICARE (July 6, 2017), https://www.justice.gov/usao-mdfl/pr/government-intervenes-lawsuitagainst-florida-compounding-pharmacy-excessive-charges.

44. Don Lipsy, Curbing Prescription Drug Compounding in Workers' Compensation, PropertyCasualty360 (Feb. 6, 2018, 1:30 AM), http://www.propertycasualty360.com/2018/02/ 06/curbing-prescription-drug-compounding-in-workers-c.

45. Scott R. Grubman \& Samuel M. Shapiro, Compounding the Problem: The Government Cracks Down on Compounding Pharmacy Fraud and Abuse, CHI. Med., May 2016, at 14.

46. Federal Food, Drug, \& Cosmetic Act, 21 U.S.C. § 321(p) (2012).

47. 21 U.S.C. $\S 351(\mathrm{a})(2)(\mathrm{B})(2012)$. 
pharmacies are generally regulated by state boards of pharmacy and are exempt from CGMPs. 48

In response to the growth in compounding and concerns over compounded drugs in the 1990s, Congress enacted the FDA Modernization Act (FDMA) in 1997 that added the new FDCA Section 503A. ${ }^{49}$ Section 503A clarified the FDA's position on regulating compounded drugs by establishing the conditions under which compounded drugs would be exempt from certain requirements of the FDCA-the new drug approval process, labeling requirements, and CGMP requirements. ${ }^{50}$ Section 503A exempts drugs from these FDCA requirements if they are compounded by a licensed pharmacist or physician upon receipt of a valid prescription for an identified patient, or in limited quantities before the receipt of a valid prescription based on a history of compounding orders from patients with whom the compounder has an established relationship. ${ }^{51}$ Section 503A also prohibits compounding, regularly or in inordinate amounts, drugs that are essentially copies of a commercially-available drug unless there is a drug shortage..$^{52}$

Following the 2012 fungal meningitis outbreak and growing concerns about the safety of compounded drugs, Congress enacted the Compounding Quality Act as part of the DQSA..$^{53}$ The DQSA added the new FDCA Section 503B that delineates a new category of drug compounding facilities-outsourcing facilities - that do not qualify for exemptions under Section 503A because they compound in large quantities without identified patient prescriptions. ${ }^{54}$ Thus, the DQSA

48. Jennifer Gudeman et al., Potential Risks of Pharmacy Compounding, 13 DRugs R\&D 1, 2 (2013).

49. Gerald Gianutsos, Regulatory and Safety Issues in Compounding, U.S. Pharmacist, Oct. 2015 , at 63,67 .

50. 21 U.S.C. $§ 353 a(a)$ (2012 \& Supp. V 2018).

51. Id. The FDA interprets the advance prescription requirement to restrict 503A pharmacies from compounding drugs to be held by hospitals, clinics, or health care practitioners for "office use." These health care entities can obtain and stock compounded drugs from 503B outsourcing facilities that are permitted to compound in large quantities without identified patient prescriptions. The restriction against 503A pharmacies compounding for office use not only protects patients by ensuring that they get compounded drugs from more strictly regulated facilities, it also encourages 503A pharmacies that would like to compound drugs for office use to transition to 503B status. However, to prevent drug shortages at hospitals, clinics, or health care practitioners, the FDA should allow 503A compounders to supply specified compounded drugs during any period when they are unavailable from 503B outsourcing facilities. U.S. FoOD \& DrUG Admin., UCM496286, Prescription Requirement Under Section 503A of the Federal Food, Drug, ANd Cosmetic Act: Guidance for Industry (2016).

52. 21 U.S.C. $\$ 353 a(b)(1)(D)(2012)$.

53. Drug Quality and Security Act of 2013, Pub. L. No. 113-54, 127 Stat. 587 (codified at 21 U.S.C. § 301 et seq. (Supp. V 2018)).

54. 21 U.S.C. $§ 353 b(d)(4)(A)-(C)$ (Supp. V 2018). 
effectively divides compounding facilities into those regulated by Section 503A ("503A compounding pharmacies") and those regulated by Section 503B ("503B outsourcing facilities"), with the key distinction being whether the facility compounds large quantities of drugs before receiving individual prescriptions.

Section 503B establishes the conditions under which drugs compounded in outsourcing facilities are exempt from the FDA's new drug approval process, from labeling requirements, and from supply chain track-and-trace requirements. ${ }^{55}$ Unlike 503A compounding pharmacies, 503B outsourcing facilities are subject to CGMP requirements, registration with the FDA, ${ }^{56}$ enhanced risk-based FDA inspections, ${ }^{57}$ and adverse event reporting. ${ }^{58}$ Thus, 503B outsourcing facilities are regulated more like the manufacturers of traditional drugs. Outsourcing facilities are also prohibited from using a bulk drug substance (i.e., active pharmaceutical ingredient) to compound a new drug unless either the Secretary of Health and Human Services has determined there is a clinical need for the bulk drug substance or there is a shortage in effect for the drug compounded from the bulk drug substance. ${ }^{59}$ Like 503A compounding pharmacies, 503B outsourcing facilities are prohibited from compounding drugs that are essentially copies of available drugs unless there is a shortage of that drug. ${ }^{60}$

\section{Regulatory Gaps in Drug Compounding}

Compounded drugs face significantly less regulatory scrutiny than do traditional drugs. Traditional drug manufacturers must undergo the arduous FDA approval process and prove that their drugs are safe and effective before marketing them to the public. In contrast, compounders need not obtain FDA approval for their drugs before selling them. Because of the different pre-market approval requirements, compounded drugs are inherently riskier than traditional new drugs.

Another regulatory gap exists in the lax oversight of 503A compounding pharmacies. Like traditional manufacturing facilities, 503B outsourcing facilities must meet CGMP requirements, face routine inspection by the FDA to ensure compliance, and report adverse events to the FDA. In contrast, 503A compounding pharmacies do not have

\footnotetext{
55. Id. $\S 353 \mathrm{~b}(\mathrm{a})$.

56. Id. $\S 353 \mathrm{~b}(\mathrm{~b})(1)$ and (3).

57. Id. $\S 353 \mathrm{~b}(\mathrm{~b})(4)$.

58. Id. $\S 353 \mathrm{~b}(\mathrm{~b})(5)$.

59. Id. $\S 353 \mathrm{~b}(\mathrm{a})(2)(\mathrm{A})$.

60. 21 U.S.C. $§ 353 b(a)(5)$.
} 
to meet CGMP requirements or report adverse events to the FDA. ${ }^{61}$ Although 503A pharmacies deemed high-risk may be inspected by the FDA, the pharmacies are not subject to routine FDA inspection. ${ }^{62}$

Moreover, whereas traditional manufacturers and 503B outsourcing facilities are supervised by the FDA, 503A compounding pharmacies are primarily overseen by state regulatory bodies. This state supervision of 503A compounding pharmacies is generally less consistent and comprehensive than FDA supervision. ${ }^{63}$ A 2015 survey of state regulatory bodies tasked with supervising compounding pharmacies in 43 states revealed that only 24 states routinely tracked in-state pharmacies dispensing compounded drugs, and only 19 states tracked out-ofstate pharmacies shipping compounded drugs into the state. ${ }^{64}$ Thus, approximately half of the states did not even track which pharmacies are engaged in compounding drugs. Moreover, only about one-third of states required compounding pharmacies to have a patient-specific prescription in advance of compounding, which is the primary requirement differentiating 503A from 503B facilities under federal law. ${ }^{65}$ In addition, only about half of the states required compounding pharmacies to meet well-established production quality standards for compounding, ${ }^{66}$ and only $40 \%$ of states required compounding pharmacies to report adverse events or reactions to the FDA or state regulatory bodies. ${ }^{67}$ A 2018 update found that the percentage of states requiring compounding pharmacies to meet well-established production quality standards increased from roughly half to over $85 \%, 68$ and the percentage of states requiring compounding pharmacies to have a patientspecific prescription in advance of compounding increased from about $35 \%$ to $78 \% .{ }^{69}$ However, the report found a decline in state inspec-

61. U.S. Food \& Drug Admin., UCM514666, Insanitary Conditions at Compounding FACILITIES: GuidANCE fOR INDUSTRy 1, 2 (2016).

62. DABrowsKa, supra note 2, at 8.

63. Best Practices for State Oversight of Drug Compounding, Pew Charitable Tr. 1-3 (Mar. 2016), https://www.pewtrusts.org/-/media/assets/2016/02/best_practices_for-state_oversight_of_ drug_compounding.pdf.

64. A. Simon Pickard et al., National Assessment of State Oversight of Sterile Drug Compounding, Pew Charitable Tr. 1, 13 (Feb. 2016), https://www.pewtrusts.org/ /media/assets/ 2016/02/national_assessment_of_state_oversight_of_sterile_drug_compounding.pdf.

65. Id. at $15-16$.

66. Id. at 10 .

67. Id. at $12-13$.

68. State Oversight of Drug Compounding: Major Progress Since 2015, But Opportunities Remain to Better Protect Patients, Pew Charitable Tr. \& Nat'L Ass'N Bds. Pharmacy 1, 5-6 (Feb. 2018), https://www.pewtrusts.org/-/media/assets/2018/02/drug_safety_assesment_web.pdf.

69. Id. at $10-12$. 
tions of compounding pharmacies; whereas 26 states conducted routine inspections in 2015, only 22 states did in the updated study. ${ }^{70}$

The disparity between the regulatory oversight of 503B outsourcing facilities compared to 503A compounding pharmacies creates strong incentives for unscrupulous compounding facilities coming under the 503B requirements to neglect to register as such. Moreover, the states do not consistently ensure that facilities claiming to be 503A compounding pharmacies meet the 503A requirements. As a result, many compounding facilities that should be supervised by the FDA as 503B outsourcing facilities are able to slip through the cracks and identify as 503A compounding pharmacies. Although the exact number of compounding facilities evading their regulatory responsibilities is unknown, routine FDA inspections suggest that the scope of the problem could be substantial. In 2016, the FDA explained that "[o]ur experience was that in the substantial majority of cases, inspected human drug compounders not registered as outsourcing facilities were compounding at least some of their drugs not in accordance with [S]ection 503A." 71 Of the over 7,500 compounding pharmacies across the country, only 73 of them have elected to register as 503B outsourcing facilities. ${ }^{72}$ This evasion of regulatory responsibility combined with the lax and inconsistent state supervision of 503A compounding pharmacies exposes patients to unnecessary risk.

\section{Closing the Regulatory Gaps in Compounding}

Compounded drugs that have not been approved by the FDA for safety and efficacy inherently pose greater risk to patients than FDAapproved drugs. However, several measures implemented by federal and state regulators could reduce the unnecessary risk arising from the regulatory gaps of compounding pharmacies.

\section{A. Encouraging Transition of Compounders to 503B Outsourcing Facilities}

The current disparity between the obligations and oversight of 503B outsourcing facilities compared to 503A compounding pharmacies gives compounders a strong disincentive to register as 503B facilities. Indeed, some compounders are skirting the law by improperly self-

70. Id. at 13 .

71. Notice, U.S. Food \& Drug Admin 1, https://www.fda.gov/downloads/drugs/guidancecom plianceregulatoryinformation/pharmacycompounding/ucm510684.pdf (last visited Jan. 28, 2019).

72. Registered Outsourcing Facilities, U.S. Food \& Drug Admin, https://www.fda.gov/Drugs/ GuidanceComplianceRegulatoryInformation/PharmacyCompounding/ucm378645.htm (last updated Feb. 19, 2019). 
identifying as 503A compounding pharmacies; the FDA has stated that in the "substantial majority" of its routine inspections of 503A pharmacies, it has found compounding practices that exceed those allowed under Section 503A. ${ }^{73}$

The patients of these unscrupulous pharmacies are exposed to unnecessary risk from drugs compounded in 503A pharmacies as opposed to drugs compounded in 503B facilities because regulation of 503A pharmacies is lax and oversight is inconsistent. Unlike 503B facilities, 503A pharmacies need not meet CGMP requirements in their manufacturing of compounded drugs, report adverse events, or undergo routine FDA inspections. Thus, drugs compounded in 503A pharmacies pose a greater risk to patient safety than drugs compounded in the more strictly regulated 503B facilities. ${ }^{74}$

To prevent compounders from skirting the law, state and federal regulators should increase inspections of self-identified 503A compounding pharmacies to confirm that they do indeed qualify for exemptions under Section 503A. Regulators should also increase the penalties imposed against compounders that knowingly try to circumvent the law. Increased inspections and enhanced penalties for noncompliance would deter many unscrupulous pharmacies from neglecting to register as a 503B facility.

In addition, in order to reduce the burden of registering as a 503B outsourcing facility, the FDA should introduce more flexible production requirements and enforcement measures that reflect the risk of facilities' compounding activities. For example, outsourcing facilities compounding smaller amounts of low-risk drugs should be subject to less onerous reporting and inspection requirements than facilities compounding riskier drugs or dispensing large quantities of compounded drugs. These and similar steps will reduce the burdens imposed on 503B outsourcing facilities and encourage some compounding facilities to transition to 503B status. The FDA has indicated that it plans to issue revised guidance and regulations that would allow for more flexibility in required production standards and FDA enforcement for 503B outsourcing facilities. ${ }^{75}$ Ultimately, the more compounding facilities subject to FDA oversight instead of inconsistent or lax state regulatory oversight, the lower the risks to patient safety.

73. Notice, supra note 71.

74. UCM536549, supra note 31 , at 8.

75. Gottlieb, supra note 26. 


\section{B. Restricting Compounded Copies of FDA-Approved Drugs}

Both Sections 503A and 503B prohibit compounding facilities from compounding drugs that are essentially copies of FDA-approved or commercially-available products unless there is a drug shortage. Nevertheless, some rogue compounders mass-produce compounded drugs that are essentially copies of commercially-available drugs. ${ }^{76}$ These compounders are exploiting and profiting from the disparate premarket approval requirements facing traditional manufacturers.

Compounded copies expose patients to unnecessary risk and threaten innovation in the drug industry. Commercially-available drugs that have undergone FDA safety reviews and premarket inspection of manufacturing quality are far safer than compounded drugs. ${ }^{77}$ Indeed, several adverse events investigated by the FDA have involved drugs that were essentially copies of commercially-available drugs, including the 2012 fungal meningitis outbreak that sickened over 800 people and caused more than 60 deaths. ${ }^{78}$ As a result, the FDA has concluded that "[b]ecause they are subject to a lower regulatory standard, compounded drugs should only be distributed to meet the needs of patients whose medical needs cannot be met by an FDA-approved drug." 79

In addition, compounded drugs that are essentially copies of FDAapproved drugs threaten incentives for pharmaceutical innovation. Pharmaceutical manufacturers, either brand name or generic, will have less incentive to invest millions or billions of dollars in new drug development if compounding facilities can effectively free ride off of their investment and sell copies of their drugs. Thus, the FDA has stated that restrictions against compounded copies "protect the incentives for conventional drug manufacturers to pursue research and to develop FDA-approved drugs." 80

The FDA recently issued two guidance documents to reiterate its position against compounded products that are essentially copies of commercially-available drugs and are compounded regularly or in inordinate amounts. ${ }^{81}$ The documents clarified that the FDA will consider a drug to be essentially a copy of a commercially-available drug if it has the same active pharmaceutical ingredient in a similar dosage

\footnotetext{
76. See, e.g., Overley, supra note 30.

77. UCM510154, supra note 24 , at 1,3 .

78. $I d$.

79. Gottlieb, supra note 26.

80. Id.

81. Id.
} 
strength and can be used by the same route of administration. ${ }^{82}$ Products compounded in violation of the restriction against copies do not qualify for the Section 503A or Section 503B exemptions. The FDA has also signaled its intention to block copycat drugs in recent draft guidance that limits the situations in which bulk drug substances can be used and restricts the specific substances that are approved for use. ${ }^{83}$

Strict enforcement of restrictions against compounded drugs that are essentially copies of FDA-approved drugs will protect patient safety and safeguard incentives to invest in new drug development. Enhanced penalties for knowing violations, such as revocation of registration or significant fines, will punish wrongdoers and deter future violations. In addition, because traditional drug manufacturers are the ones most likely to know when compounders are making copies of their drugs, the FDA should create a formal mechanism for them to report violations.

\section{Improving Regulation of Bulk Drug Substances}

The FDA has been working to establish a list of bulk drug substances allowed in compounding by 503B outsourcing facilities since the DQSA's enactment in 2013. Until the list is finalized, the FDA generally allows compounding with any drug substance that a compounder has nominated for the final list as long as it is nominated with sufficient information for the FDA to eventually evaluate the substance and does not present a significant safety risk. ${ }^{84}$ This interim policy sharply contrasts with Congress's intent in the DQSA that a bulk drug substance could not be used for compounding by a 503B outsourcing facility unless there was a clinical need determined after a notice and comment period. ${ }^{85}$ This notice and comment period was intended to allow other industry participants to challenge the nomination of a bulk drug substance when, for example, a safer FDA-approved drug could meet the clinical need. In contrast, under the interim policy, there is no formal mechanism to oppose the nomination of a bulk drug substance before it is used in compounding.

This interim policy exposes patients to unnecessary risk by allowing compounding with ingredients that have not yet been properly evaluated for safety and quality. As the FDA explains: "There are fewer

82. UCM510154, supra note 24, at 5-6.

83. See generally UCM602276, supra note 32.

84. UCM469122, supra note 33, at 5-8.

85. Drug Quality and Security Act of 2013, Pub. L. No. 113-54, § 102(a)(2)(A), 127 Stat. 587, 588 (codified at 21 U.S.C. $§ 353$ (b) (Supp. V 2018)). 
assurances of safety and quality associated with a bulk drug substance than with an FDA-approved drug." 86 It also enables compounders to effectively recreate FDA-approved drugs using bulk drug substances, "undermin[ing] the drug approval process by reducing the incentive for drug manufacturers to seek approval of brand or generic drugs." 87 Moreover, some compounders are flagrantly violating the interim policy by compounding with ingredients that have not even been nominated to the final list. ${ }^{88}$

The FDA should strictly enforce violations of the interim policy to reduce patients' exposure to unsafe ingredients. In addition, rather than wait until the bulk drug substances list is finalized, the FDA should create a mechanism to allow challenges to the ingredients under the interim policy. This mechanism would align with Congress's intent to allow bulk drug substances to be used in compounding by 503B outsourcing facilities only after they have gone through a notice and comment period. Allowing challenges will also provide more information to the FDA as it determines the safety and clinical need of bulk ingredients.

\section{Increasing FDA Oversight of Compounding Facilities}

Since the enactment of DQSA in 2013, the FDA has conducted more than 425 inspections of compounding facilities, including both routine inspections of $503 \mathrm{~B}$ outsourcing facilities and risk-based inspections of 503A compounding pharmacies. From these inspections, the FDA has issued more than 160 warning letters advising compounders of violations of federal law or unsanitary conditions. The FDA follows up on these letters by making sure the facilities have taken appropriate corrective actions. The FDA has also overseen over 140 recalls of compounded drugs due to possible contamination or

86. Press Release, U.S. Food \& Drug Admin., Statement from FDA Commissioner Scott Gottlieb, M.D., on a Key Step in Advancing FDA's Oversight of Drug Compounding and Implementing New Laws Governing Outsourcing Facilities (Mar. 23, 2018), https://www.fda.gov/ NewsEvents/Newsroom/PressAnnouncements/ucm602316.htm.

87. Id.

88. See, e.g., FDA Investigates Two Serious Adverse Events Associated with ImprimisRx's Compounded Curcumin Emulsion Product for Injection, supra note 21. Curcumin has not been nominated for the 503B bulk drug substances list. See Bulk Drug Substances Nominated for Use in Compounding Under Section 503B of the Federal Food, Drug, and Cosmetic Act, U.S. Food \& Drug Admin., https://www.fda.gov/downloads/Drugs/GuidanceComplianceRegulatoryInforma tion/PharmacyCompounding/UCM467374.pdf (last updated Mar. 1, 2019); see also Letter from Ron Pace, Dist. Dir., N.Y. Dist. Food \& Drug Admin., to Alfonse Muto, Owner, Pine Pharmacy \& Home Care Products Ctr., Inc. (Feb. 13, 2015), https://www.fda.gov/ICECI/EnforcementAc tions/WarningLetters/2015/ucm434868.htm (showing that domperidone and Brilliant Blue G have not been nominated to the 503B bulk drug substances list). 
other drug quality issues. ${ }^{89}$ The enhanced FDA oversight of compounding facilities required under the DQSA has been effective in reducing some of the risk associated with compounded drugs. Many compounders have taken corrective actions to improve production conditions that could lead to contamination, and others have voluntarily recalled potentially contaminated drugs and halted production until corrective actions could be taken. ${ }^{90}$ Yet much remains to be done to protect patient safety.

Compounding pharmacies continue to engage in compounding under unsanitary conditions. In recent inspections of compounding facilities, the FDA has observed "dog beds and dog hairs in close proximity to a sterile compounding room, dead insects in ceilings, renovations made without any evidence of controls to protect sterile drugs from contamination, and use of coffee filters to filter particulates." 91 Adverse events from compounding continue to jeopardize patient safety. As recently as 2017, the FDA has responded to the following case reports: at least 43 patients in Texas that experienced vision loss after receiving compounded eye injections, 2 patients in California (including 1 who died) that had severe reactions to a compounded injectable not suitable for human use, 1 patient in Texas that experienced paralysis from a compounded injectable, 41 patients in New Jersey that experienced septic arthritis from a contaminated compounded injectable, 1 patient in New Jersey that experienced retinal vascular occlusion and hemorrhage from a compounded injectable, and 2 patients in Florida that experienced tissue erosion from a compounded injectable. ${ }^{92}$

An increase in FDA inspections of both 503B outsourcing facilities and 503A compounding pharmacies engaging in risky compounding would bring to light additional problematic conditions. To facilitate the FDA's assessment of pharmacies' risk levels, both the FDA and state regulators should cooperate in the collection and exchange of information that is relevant to the compounding risk. For example, enhanced recordkeeping about adverse events, types of compounded drugs, quantity of compounded drugs dispensed, compounded drugs shipped across state lines, and production processes will assist the

89. See Woodcock \& Dohm, supra note 3, at 2510.

90. UCM536549, supra note 31 , at 3.

91. Id.

92. Woodcock \& Dohm, supra note 3, at 2510; U.S. Illnesses and Deaths Associated with Compounded Medications or Repacked Medications, 2001-17, Pew Charitable Tr. (June 23, 2017), http://www.pewtrusts.org/en/multimedia/data-visualizations/2017/us-illnesses-and-deaths-associat ed-with-compounded-medications-or-repackaged-medications (noting that the "chart was updated in February 2019 to include newly reported adverse events"). 
FDA in risk assessment. Ultimately, better information tracking and more FDA inspections will reduce the ability of 503A compounding pharmacies to exploit the regulatory gaps that currently put patient safety at risk.

\section{E. Expanding State Oversight of 503A Compounding Pharmacies}

Even with enhanced FDA oversight, many compounders will continue to be overseen by state regulatory bodies. Yet, over fifty percent of states currently do not conduct routine inspections of 503A compounding pharmacies. Fifteen percent of states do not require compounding pharmacies to meet well-established production quality standards. Twenty percent of states do not require pharmacies to have a patient-specific prescription in advance of compounding (even though an advance prescription is generally required under federal law). ${ }^{93}$ With such lax and inconsistent oversight, unsafe and unlawful compounding practices are sure to occur, imperiling patient safety.

While the FDA should focus its oversight efforts on 503B outsourcing facilities and high-risk 503A compounding pharmacies, states should improve their routine supervision of low-risk compounders that meet the conditions for 503A exemption. More consistent and stringent supervision of 503A compounding pharmacies by state regulatory bodies will reduce the disparate oversight between 503B and 503A facilities, improving drug safety and quality. In addition, devoting more state funding to the regulation of compounding pharmacies will eliminate some regulators' claims that inadequate "financial resources and inspection capacity" 94 preclude them from conducting routine inspections.

Although the FDA and some states are taking steps to develop best practices for supervising 503A compounding pharmacies, more work must be done to establish consistent approaches among the states. ${ }^{95}$ Consistent practices will ensure that the FDA can focus its oversight efforts on the high-risk compounding practices while states conduct the routine oversight of low-risk compounders within their borders and appropriately communicate problems to the FDA.

\section{CONCLUSION}

Drug compounding has grown from an occasional practice of local pharmacists to a sizable industry with over 7,500 specialized com-

93. State Oversight of Drug Compounding, supra note 68, at 5, 11-13.

94. State Oversight of Drug Compounding, supra note 68, at 2.

95. Gottlieb, supra note 26. 
pounding pharmacies and 40 million annual prescriptions for compounded drugs. Unfortunately, as compounding has expanded, it has effectively outgrown the regulatory structure developed when the industry was in its infancy. The resulting gaps in regulation have led to drug safety problems, fraudulent practices, and anticompetitive behaviors.

This Article advocates for several specific proposals to close these regulatory gaps. In general, more consistent and thorough inspections of compounders by both the FDA and state agencies will identify problematic conditions and mitigate some of the risk associated with compounded drugs. Increased inspections of self-identified 503A compounding pharmacies will also confirm that the facilities do indeed qualify for 503A status. In addition, greater communication and cooperation between state agencies and the FDA will help to identify and monitor facilities engaged in risky compounding and to ensure more consistent oversight of these facilities. Enhanced penalties for noncompliance-such as compounding unnecessary copies of FDA-approved drugs, improperly self-identifying as a 503A compounding pharmacy, and violating the bulk drug substances interim policy-will protect patients from unnecessary exposure to risky drugs and safeguard incentives for new drug development. Finally, a formal mechanism to allow industry participants to notify the FDA of illegal compounded copies and to challenge nominations for the bulk drug substances list will provide important information to the FDA and promote patient safety. Ultimately, these or similar measures will protect patients, payors, and innovation in the pharmaceutical industry. 
406

DEPAUL LAW REVIEW

[Vol. 68:385 